\title{
ANTIOXIDANT, ANTIMICROBIAL AND PHOTOCATALYTIC ACTIVITIES OF SILVER NANOPARTICLES OBTAINED BY BEE PROPOLIS EXTRACT ASSISTED BIOSYNTHESIS
}

\author{
ANDREIA CORCIOVĂ ${ }^{1 \#}$, CORNELIA MIRCEA ${ }^{1 *}$, ANA-FLAVIA BURLEC ${ }^{1 \#}$, OANA CIOANCA $^{1}$, \\ CRISTINA TUCHILUŞ ${ }^{2 \#}$, ADRIAN FIFERE ${ }^{3}$, ANA-LĂCRĂMIOARA LUNGOCI ${ }^{3}$, NARCISA \\ MARANGOCI $^{3}$, MONICA HĂNCIANU ${ }^{1}$ \\ 1"Grigore T. Popa” University of Medicine and Pharmacy, Faculty of Pharmacy, 16 Universităţii Street, 700115, Iași, Romania \\ 2 "Grigore T. Popa” University of Medicine and Pharmacy, Faculty of Medicine, 16 Universității Street, 700115, Iași, Romania \\ 3 "Petru Poni" Institute of Macromolecular Chemistry, Center of Advanced Research in Bionanoconjugates and Biopolymers, \\ 41 A Grigore Ghica-Vodă Alley, 700487, Iaşi, Romania
}

*corresponding author: corneliamircea@yahoo.com

${ }^{\#}$ Authors with equal contribution

Manuscript received: September 2018

\begin{abstract}
Taking into consideration the advantages of green synthesis of nanoparticles, the present study focuses on the formation, characterization and evaluation of some biological activities of silver nanoparticles (AgNPs) obtained using bee propolis extract. The total phenolic and total flavonoid contents were evaluated. The formation of AgNPs was primarily confirmed by the change in colour and by the appearance in the UV-Vis spectrum of the characteristic silver surface plasmon resonance band. Several compounds that can participate in the reduction process were identified by characteristic peaks of functional groups in the FTIR spectra. The presence of elemental silver was confirmed by Energy-dispersive X-ray (EDX) spectroscopy. Morphological study of AgNPs was carried out using Transmission electron microscopy (TEM) and confirmed the spherical shape. The investigated propolis extract is a valuable source of compounds which can participate in the synthesis of AgNPs with antimicrobial, antioxidant and photocatalytic degradation properties.
\end{abstract}

\section{Rezumat}

Deoarece sinteza verde a nanoparticulelor prezintă o serie de avantaje, studiul de faţă se axează pe obținerea, caracterizarea și evaluarea unor activități biologice ale nanoparticulelor de argint (AgNPs) preparate prin utilizarea unui extract de propolis. A fost evaluat conținutul total în polifenoli și conținutul total de flavonoide. Formarea AgNPs a fost confirmată în primul rând prin schimbarea culorii și prin apariția în spectrul UV-Vis a benzii caracteristice rezonanței plasmonice de suprafață. Din spectrele FTIR au fost identificați mai mulți compuși care pot participa la procesul de reducere, prin picurile caracteristice grupărilor funcționale. Prezența argintului elemental a fost confirmată prin spectroscopia EDX. Studiul morfologic al AgNPs a fost realizat folosind microscopia electronică prin transmisie (TEM), care a confirmat forma sferică a nanoparticulelor. Rezultatele arată că extractul de propolis este o sursă importantă de compuși care pot participa la sinteza AgNPs cu proprietăți antimicrobiene, antioxidante și fotocatalitice.

Keywords: nanotechnology, antioxidant, antimicrobial, photocatalytic degradation

\section{Introduction}

Nanotechnology and particularly nanoparticles, metal atom clusters with a size range of $1-100 \mathrm{~nm}$ [11], offer numerous applications in various fields, such as human health, biomedical and environmental sciences, industry and engineering [2]. Among all types, silver nanoparticles (AgNPs) are the most common and are considered important because it has been shown to have various activities such as antibacterial properties against a wide range of human pathogens [23], antifungal, antiviral, catalytic [20], antioxidant, anticancer, anti-inflammatory, hepato-protective and larvicidal effects [12].
Since the purpose of nanotechnology is represented by the synthesis of nanoparticles with well-defined shapes and sizes and with a controlled monodispersity, literature provides several methods of synthesis [36]. Among these, the preparation of AgNPs using plants is a widespread method because it is proven to be eco-friendly [35], simple, nontoxic, rapid, using less energy and involving low costs [24]. Several types of extracts can be used for the synthesis of AgNPs such as: leaf extracts: Lonicera japonica [25], Ocimum tenuiflorum [28], peel extracts: Citrus sinensis [18], Citrus fruits (orange, grape fruit, tangelo, lemon, lime) [17], Acacia [47], seed extracts: Elaeocarpus granitrus [8], fruit extract: Tribulus terrestris [10], latex: Jatropha curcas [3], bark extract: Cinnamon zeylanicum [39], 
FARMACIA, 2019, Vol. 67, 3

plant extract: Artemisia nilagirica [48], bulb extract: Allium sativum [38], flower extract: Tagetes erecta [32]. During the synthesis of AgNPs, plant extracts act both as reducing and stabilizing agents. Since extracts contain a variety of compounds that can participate in the formation of AgNPs, the process is relatively complex. Among the substances that can contribute to the bioreduction process, several classes of plant metabolites are mentioned: flavonoids, proteins and terpenoids from Ocimum sanctum [1], Chenopodium album [8], Acalypha indica [21], hydroxyflavones and catechins from Carica papaya [15], Trianthema decandra [9], alkaloids from Zingiber officinalis [42] etc.

Bee propolis has been known for a long time, being used in folk medicine [41]. It is a honeybee product, a resinous mixture with a complex chemical composition influenced by different factors like climate zones, season, vegetation and environmental conditions [6, 41].

The chemical composition includes compounds from different classes such as: resins, waxes [41], amino acids, polyphenols [6], steroids, terpenoids [6, 41], fatty acids, carbohydrates, chalcones and vitamins [37].

Some of the biological properties of propolis mentioned by literature are antibacterial, antifungal, antitumor, anti-inflammatory $[6,37,41]$, antiviral [37, 41], antioxidant [41], immunomodulatory $[6,41]$, antiprotozoal [37], analgesic/anaesthetic [6, 37].

Phenolic compounds are important constituents of plants and are recognized to have reducing properties, therefore can be used in the process of reducing silver ions to AgNPs. Thus, in the present study we evaluated the total phenolic and the total flavonoid contents of the aqueous bee propolis extract. In addition, we described a rapid biosynthesis method for AgNPs using the aforementioned extract. The obtained nanoparticles were further characterized by UV-Vis, FTIR, EDX spectroscopy and TEM analysis. Antibacterial, antioxidant and photocatalytic activities were also evaluated.

\section{Materials and Methods}

\section{Materials}

Propolis aqueous extract (30\%) produced in the Iași area (Romania) was purchased from a local market and appropriate dilutions were made. Quercetin, gallic acid, Folin-Ciocâlteu reagent, silver nitrate $\left(\mathrm{AgNO}_{3}\right)$, aluminium chloride, sodium bicarbonate, sodium nitrite, sodium hydroxide, 1,1-diphenyl, 2-picrylhydrazyl, lipoxygenase and linoleic acid were purchased from Sigma-Aldrich (USA).

\section{Total phenolic and flavonoid contents}

The total phenolic content was determined using the Folin-Ciocâlteu method with some modifications [7, 43]. Briefly, the samples (extract and the supernatant after AgNPs separation) in proper dilution were treated with Folin-Ciocâlteu reagent (1:10 dilution) and a $7.5 \%$ sodium bicarbonate solution. After 2 hours, the absorbances were measured at $760 \mathrm{~nm}$. The calibration curve of gallic acid $(0.5-5 \mathrm{mg} / \mathrm{mL}$ range) used for the determination of total phenols showed a good linear correlation coefficient $\left(\mathrm{R}^{2}=\right.$ 0.9989). Results were expressed as $\mathrm{mg}$ gallic $\mathrm{acid} / \mathrm{mL}$ (mg GAE/mL).

Determination of the total flavonoid content was carried out following the aluminium chloride colorimetric method [7, 13]. Briefly, the samples (extract and the supernatant after AgNPs separation) were treated with sodium nitrite $(5 \%)$, aluminium chloride $(10 \%)$ and sodium hydroxide $(1 \mathrm{M})$. The absorbances were measured at $510 \mathrm{~nm}$. The quantitative determination of flavonoids was possible using a calibration curve of quercetin $(0.0625-1 \mathrm{mg} / \mathrm{mL}$ range) with good linearity $\left(\mathrm{R}^{2}=0.9919\right)$. Results were expressed as mg quercetin/mL $(\mathrm{mg} \mathrm{QE} / \mathrm{mL})$.

Synthesis of silver nanoparticles

For the AgNPs synthesis, $1 \mathrm{~mL}$ of $10 \%$ propolis extract and $9 \mathrm{~mL}$ of $5 \mathrm{mM} \mathrm{AgNO}_{3}$ were mixed using a magnetic stirrer at room temperature. The reaction was visually monitored by colour change and the UV-Vis spectrum was periodically checked. The colloidal solution of the synthesized nanoparticles was centrifuged at 10,000 rpm, for 30 minutes. This process was repeated three times by redispersing the product into water, and the final AgNPs were separated and dried.

Characterization of AgNPs

AgNPs synthesis was monitored by recording the UV-Vis spectrum using a Jasco V530 double beam UV-Vis spectrophotometer. The scanning speed was $1000 \mathrm{~nm} / \mathrm{min}$. The FTIR measurements were done using an FTIR Bruker Vertex 70 (USA) with a scanning range of $4000 \mathrm{~cm}^{-1}$ to $310 \mathrm{~cm}^{-1}$, and the samples were incorporated in $\mathrm{KBr}$ discs for acquiring the spectra. Average particle size and zeta potential of the synthesized AgNPs were analysed using the Delsa Nano Submicron Particle Size Analyzer (Beckman Coulter, USA). The presence of elemental silver in AgNPs was determined using a Quanta 200 Environmental Scanning Electron Microscope (ESEM) with Energy dispersive X-ray (EDX silicon-drift detector). Transmission electron microscopy (TEM) (Hitachi High-Tech HT7700 Transmission Electron Microscope, Japan) was used for the determination of surface morphology and size.

In vitro antimicrobial assay

Antimicrobial activity was evaluated by agar diffusion method, using Mueller-Hinton medium (HiMedia, Germany) for fungi and Mueller-Hinton agar (Oxoid, UK) for bacteria. The tested microorganisms, available in from the Culture Collection of the Department of Microbiology, "Gr. T. Popa” University of Medicine and Pharmacy, Iași, Romania were: Staphylococcus aureus (S. aureus) ATCC 25923, Pseudomonas 
FARMACIA, 2019, Vol. 67, 3

aeruginosa (P. aeruginosa) ATCC 27853 and Candida parapsilosis (C. parapsilosis) ATCC 22019. After the application of the samples (extract and AgNPs) and incubation at $24^{\circ} \mathrm{C}$ for fungi and 24 hours at $37^{\circ} \mathrm{C}$ for bacteria, inhibition zones in $\mathrm{mm}$ were measured [14]. Discs containing ciprofloxacin $(5 \mu \mathrm{g} /$ disc $)$ and nystatin $(100 \mu \mathrm{g} / \mathrm{disc})$ were used as positive controls. All experiments were performed in triplicate and the results were expressed as mean \pm standard deviation. In vitro antioxidant activity

Inhibition of lipoxygenase activity and free radical scavenging activity - DPPH (1,1-diphenyl, 2-picrylhydrazyl) methods were used to evaluate the antioxidant activity.

The first method is based on the ability of the samples to block lipoxygenase activity (modified Malterud method) [29]. 10 minutes after the samples (extract and AgNPs) were treated with lipoxygenase, linoleic acid in borate buffer $\mathrm{pH}=9$ was added and the absorbance was recorded, in the 30 - 90 seconds range at $234 \mathrm{~nm}$. The lipoxygenase inhibition activity of the samples was calculated.

The second method is based on the capacity of samples to neutralize the DPPH radical. The DPPH solution was added to the samples (extract and AgNPs) and the absorbance was measured after 10 minutes at $517 \mathrm{~nm}[34,45,46]$. The scavenger activity of the samples was calculated.

For samples that achieved 50\% inhibition/scavenger activity, the $\mathrm{IC}_{50}$ value was calculated. All experiments were performed in triplicate and the results were expressed as mean \pm standard deviation.
Study of photocatalytic activity of AgNPS

The photocatalytic activity of the synthesized AgNPs has been studied, observing the degradation of malachite green under sunlight irradiation. $10 \mathrm{mg}$ of AgNPs were added in $50 \mathrm{~mL}$ of malachite green solution $(10 \mathrm{mg} / \mathrm{L})$ and the mixture was stirred magnetically for 45 minutes in the dark. The colloidal suspension was afterwards exposed to sunlight, under constant irradiation, at room temperature, with continuous stirring [27]. The colour change was monitored over time and samples were taken every 30 minutes and centrifuged. The supernatant was scanned in the $400-800 \mathrm{~nm}$ range.

Simultaneously, a control containing only the dye was subjected to the same conditions and a sample containing suspension prepared from AgNPs in dye solution, constantly stirred in the dark, was also analysed.

\section{Results and Discussion}

Quantification of total phenolic and flavonoid contents Total phenolic and total flavonoid contents of the bee propolis extract and of the supernatant after AgNPs separation were determined (Table I).

As can be observed, the propolis extract is rich in phenolic and flavonoidic compounds, and the amount found in the supernatant decreases after separation of AgNPs. This demonstrates that such compounds with high reducing capacity participate in the synthesis of AgNPs, acting as reducing agents and are oxidized by silver cations.

Table I

Total phenolic and flavonoid contents of the propolis extract and of the supernatant after AgNPs separation

\begin{tabular}{|c|c|c|}
\hline Sample & Total phenolic content $(\mathrm{mg} \mathrm{GAE} / \mathrm{mL})$ & Total flavonoid content $(\mathrm{mg}$ QE $/ \mathrm{mL})$ \\
\hline Propolis extract & 14.72 & 0.9727 \\
\hline Supernatant after AgNPs separation & 0.71 & 0.1606 \\
\hline
\end{tabular}

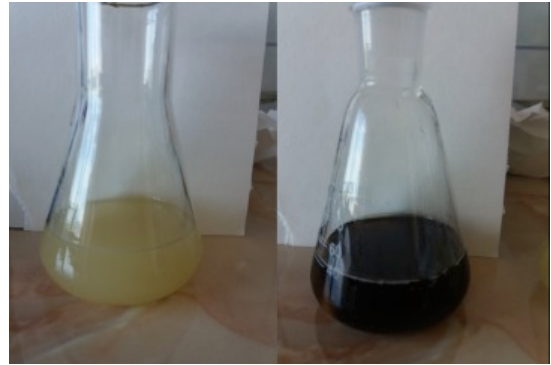

$\mathrm{a}$

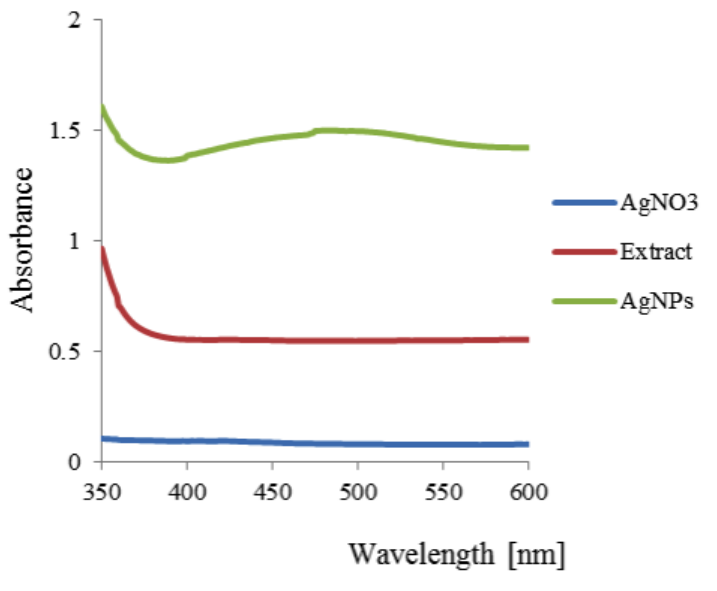

b

Figure 1.

(a) The colour of the extract:silver nitrate mixture, initial and final; (b) UV-Vis spectra of silver nitrate, extract and AgNPs 
Visual and $U V$-Vis analysis

AgNPs biosynthesis was observed in time through the change of colour of the reaction mixture from white-yellowish to brown (Figure 1a). It is well known that this colour change is due to the excitation of surface plasmon vibrations in AgNPs [40].

The surface plasmon resonance was identified by recording the UV-Vis spectrum of the mixture extract: silver nitrate, after continuous stirring, in the 350 to $600 \mathrm{~nm}$ wavelength range (Figure 1b).
After 4 hours, an absorption peak was observed around $480 \mathrm{~nm}$, which represents a spectroscopic signature for the formation of AgNPs. This peak does not appear in the extract or silver nitrate spectra. The broadening shape of the peak indicates that the AgNPs are polydispersed [16].

TEM analysis

TEM analysis (Figure 2) was used to monitor the size and morphology of the synthesized AgNPs.
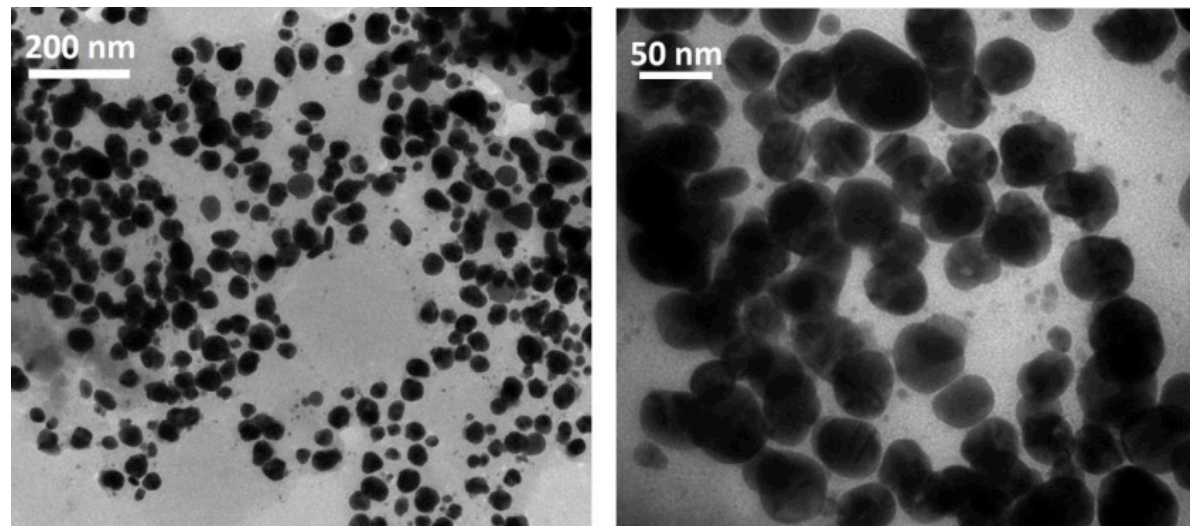

Figure 2.

TEM image of AgNPs at different magnifications

Most AgNPs displayed a spherical shape and ranged in size from $10 \mathrm{~nm}$ to $50 \mathrm{~nm}$, having an average size of approximately $15 \mathrm{~nm}$. The TEM images highlight a week tendency of aggregation, which may be based on the extract's contribution to AgNPs stabilization. Determination of Zeta potential and Dynamic light scattering (DLS)

The coating of AgNPs with polyphenolic compounds present in the propolis extract resulted in a negative zeta potential of $-21.36 \mathrm{mV}$. This suggests that the colloidal nanoparticle suspension is stable [33] and the negatively charged surface of the AgNPs prevents particle aggregation by rejection between particles [32]. DLS measurements indicated for AgNPs an average size of $14.9 \pm 0.1 \mathrm{~nm}$. This particle size value complies with the estimated values obtained from TEM.

EDX analysis

The EDX analysis was conducted at an accelerating voltage of $20 \mathrm{kV}$ and was used to quantify the elements forming the chemical composition of AgNPs (Figure 3).

The results obtained from the EDX spectrum of AgNPs confirmed the presence of elemental silver by peak pattern at $3 \mathrm{KeV}$ in the silver region [26]. The obtained AgNPs are pure, given the fact that there are no other signals corresponding to other metallic elements [44]. The most important elements forming the chemical composition of AgNPs besides silver $29.55 \mathrm{Wt} \%$ were carbon $53.26 \mathrm{Wt} \%$, oxygen 14.06 $\mathrm{Wt} \%$ and nitrogen $03.12 \mathrm{Wt} \%$, indicating the presence of compounds attached to nanoparticles.

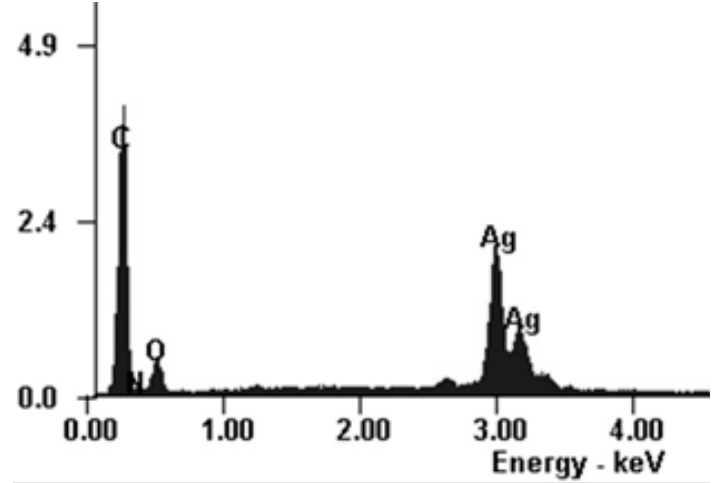

Figure 3.

EDX spectrum of AgNPs

FTIR analysis

In order to identify the biomolecules found in the propolis extract that are responsible for the reduction process, capping and stabilization of AgNPs, FTIR analysis (Figure 4) was used.

The functional groups from the propolis extract were recorded at: $3403 \mathrm{~cm}^{-1}$ corresponding to stretching vibration of $\mathrm{OH}$ from phenolic compounds, $2919 \mathrm{~cm}^{-1}$ and $2849 \mathrm{~cm}^{-1}$ probably due to stretching vibration of $\mathrm{C}-\mathrm{H}, 1635 \mathrm{~cm}^{-1}$ mainly due to stretching vibration of $\mathrm{C}=\mathrm{C}, \mathrm{C}=\mathrm{O}$ groups from flavonoids and asymmetric bending vibration of $\mathrm{N}-\mathrm{H}$ from amino acids, $1514 \mathrm{~cm}^{-1}$ due to stretching $\mathrm{C}=\mathrm{C}$ of aromatic ring, $1449 \mathrm{~cm}^{-1}$ corresponding to the bending vibration of $\mathrm{C}-\mathrm{H}$ from $\mathrm{CH}_{3}, \mathrm{CH}_{2}$ and the stretching vibration of aromatics from flavonoids and aromatic rings, $1264 \mathrm{~cm}^{-1}$ due to 
FARMACIA, 2019, Vol. 67, 3

C-O group of polyols (hydroxyflavonoids), $1082 \mathrm{~cm}^{-1}$ corresponding to $\mathrm{C}-\mathrm{O}$ stretching ester group, $815 \mathrm{~cm}^{-1}$ probably due to aromatic ring vibration and $698 \mathrm{~cm}^{-1}$ due to phenyl group [31].

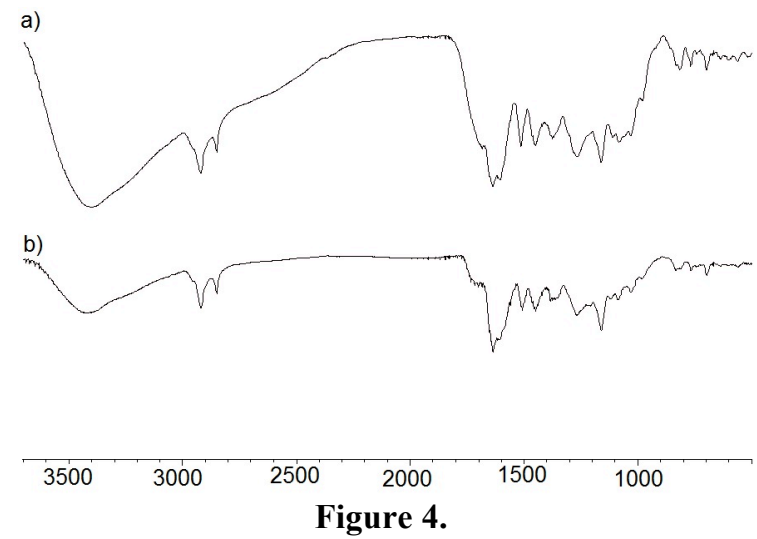

FTIR spectra of propolis extract (a) and AgNPs (b)

Among these, some peaks in the FTIR spectra of AgNPs shifted or disappeared, demonstrating that certain groups of some polyphenols, flavonoids or amino acids participate in the formation of nanoparticles.

\section{Antimicrobial and antioxidant activities}

The AgNPs and the propolis extract were tested for antimicrobial activity against a Gram-positive bacterial strain (S. aureus) and against a Gram-negative bacterial strain $(P$. aeruginosa). The antifungal activity study was carried out on $C$. parapsilosis. The diameter of the inhibition zones was measured in millimetres $(\mathrm{mm})$ and the results are presented in Table II.

The extract, in the concentration taken into work, did not present antibacterial nor antifungal activities. However, both $S$. aureus and $P$. aeruginosa were susceptible to the influence of AgNPs. The observed antibacterial activity of the AgNPs was higher against
Gram-positive bacteria (S. aureus). The explanation could be the difference in molecular makeup of the cell walls [26]. Literature presents different results: some demonstrate that AgNPs have higher activity against Gram-positive than against Gram-negative bacteria [19], while other results lead to opposite conclusions [33].

To explain the antibacterial mechanism of AgNPs, there are several possible interpretations. AgNPs could be a source of reactive oxygen species which damage bacteria proteins and DNA, leading to the alteration of cell membrane permeability and to bacterial membrane destruction [30]. AgNPs could also interact with sulphur containing proteins after adhering to the surface of the bacterial cell membrane, leading to permeability alteration and finally to cell death [19]. Furthermore, the association of antimicrobial activity of the nanosilver form and the presence of some compounds with antimicrobial properties like phenols and flavonoids contributes to the increase of the antimicrobial activity of AgNPs. This can be explained by the increase in surface:volume ratios in the nanoparticles, fact which implies maximum contact area with the bacteria [26]. The synthesized AgNPs show antifungal activity on $C$. parapsilosis that could be explained by the interaction between AgNPs and compounds with phosphorus and sulphur causing protein and DNA damage with destruction of membrane integrity [22].

The antioxidant activity of the propolis extract and of the synthetized AgNPs was evaluated using DPPH free radical scavenging assay and lipoxygenase inhibition assay. The $\mathrm{IC}_{50}$ for the samples that achieved $50 \%$ inhibition/scavenger activity, are presented in Table II.

Antibacterial and antioxidant activities of propolis extract and AgNPs

\begin{tabular}{|c|c|c|c|c|c|}
\hline \multirow{2}{*}{ Sample } & \multicolumn{2}{|c|}{ Antibacterial activity Diameter of inhibition zones $(\mathrm{mm})$} & \multicolumn{2}{c|}{ Antioxidant activity } \\
\cline { 2 - 6 } & S. aureus & P. aeruginosa & C. parapsilosis & DPPH method & Lipoxygenase inhibition assay \\
\hline Extract & 0 & 0 & 0 & $33.65 \pm 0.03 \mathrm{mg} / \mathrm{mL}$ & - \\
\hline AgNPs & $10 \pm 0.1$ & $2 \pm 0$ & $9 \pm 0.2$ & $0.45 \pm 0.005 \mathrm{mg} / \mathrm{mL}$ & $8.15 \pm 0.09 \mu \mathrm{g} / \mathrm{mL}$ \\
\hline
\end{tabular}

The obtained $\mathrm{IC}_{50}$ values demonstrate that AgNPs exhibit a better antioxidant activity than the extract, which can be explained, on the one hand, by the presence of silver which can easily lose electrons [30], and on the other hand because of the higher content of biomolecules with antioxidant activity from the surface of AgNPs. It seems that after the silver reduction followed by the formation of nanoparticles; the AgNPs preferentially adsorb biomolecules with antioxidant properties in detriment of others present in the propolis extract. Hence, the suspension of AgNPs is rich mainly in polyphenolic compounds. This statement is also demonstrated by the results found in Table I, where a decrease in the total phenolic and flavonoid contents is observed. Thus, the supernatant has 6.05 times less flavonoids and 20.73 times fewer phenolic compounds.

Moreover, regarding the lipoxygenase inhibition assay, compounds from the plant extract found on the metal surface determine large-sized AgNPs and thus, the access of the substrate to the active site of the enzyme is prevented. 
Analysis of photocatalytic activity

The photocatalytic activity of the synthesized AgNPs was determined by monitoring malachite green degradation under sunlight for a certain period of time. Malachite green (N-methylated diaminotriphenylmethane) is a colorant used in different kinds of industries. Both malachite green and its reduced form can be found in aquatic and terrestrial ecosystems and therefore represent a potential hazard to human health [4].

Initially, the photocatalytic degradation was visually observed by colour change, the intensity gradually decreasing from dark blue to light blue (Figure 5a). Subsequently, the decrease in colour was spectrophotometrically monitored by recording the absorbance at $617 \mathrm{~nm}$, which is the wavelength of the most important peak in the dye spectrum (Figure 5b).

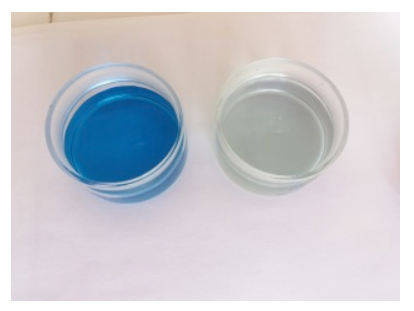

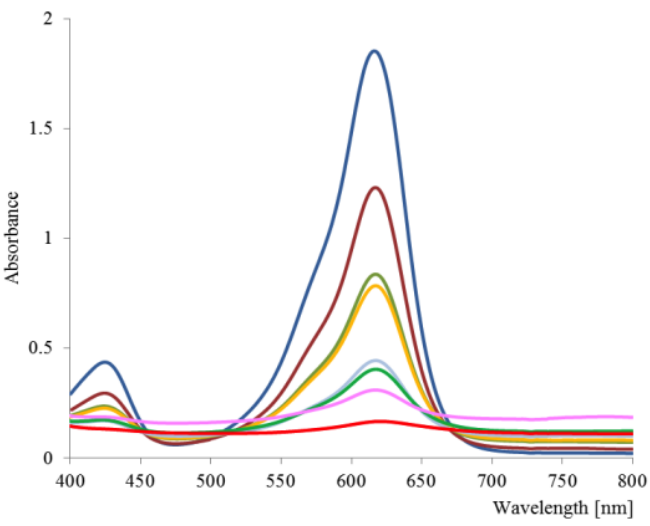

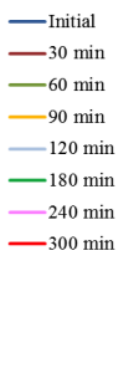

Figure 5.

(a) Photocatalytic degradation - colour change; (b) UV-Vis spectra which indicates the photocatalytic degradation of malachite green in time

An important decrease in absorbance over time can be noted, indicating a decrease in dye concentration, due to its degradation. The control containing only the dye did not show any change in colour during exposure to sunlight and for the sample mixed in the dark, the decrease in colour and absorbance was low.

Also, dye degradation (\%) (Figure 6) was calculated using the following formula:

$$
\text { Dyedegradation } \%=\frac{C_{0}-C_{t}}{C_{0}} \times 100,
$$

where $\mathrm{C}_{0}$ is the initial concentration of malachite green, $\mathrm{C}_{\mathrm{t}}$ is the concentration of malachite green after each period of exposure time to sunlight [27].

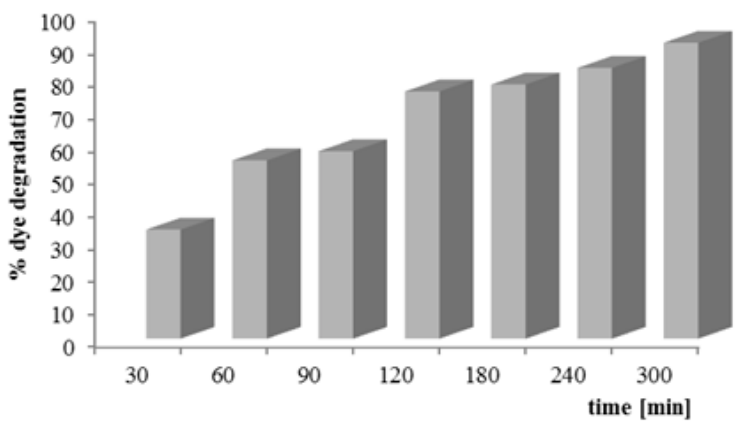

Figure 6.

Dye degradation (\%) in time
For the sample exposed to sunlight, the dye degradation was $90 \%$, for the control the degradation was $5 \%$ and for the sample mixed in the dark, 30\%. This demonstrates that the obtained AgNPs are highly photo-catalytically active under light radiation.

It is supposed that, during sunlight exposure, visible light radiation photons reaching the AgNPs are absorbed through the surface plasmon resonance effect and cause the excitation of electrons to a higher energy state. At the same time, AgNPs absorb UV radiation due to transitions between $4 \mathrm{~d}$ and $5 \mathrm{~s}$ orbits, and photogenerated electrons have high energy. As a result, oxygen molecules dissolved in the reaction medium accept excited electrons and are transformed into radical superoxide anions $\left(\cdot \mathrm{O}_{2}^{-}\right)$and hydroxyl radicals (HO•), which break the dye into simpler organic molecules, causing a rapid degradation [5].

Therefore, AgNPs can act as a stable and efficient photo-catalyst for the degradation of dye under irradiation with light from the full solar spectrum.

\section{Conclusions}

The use of plants for nanoparticles formation is an advantage due to their accessibility and to the variety of biomolecules that can participate in the synthesis process. The purposes of this study were to obtain AgNPs using an aqueous propolis extract and to characterize the synthesized nanoparticles. The wavelength of the surface plasmon resonance was $434 \mathrm{~nm}$. 
FTIR analysis demonstrated the presence of functional groups that can participate in the synthesis of nanoparticles. Through EDX, the presence of elemental silver was proved. The zeta potential of synthesized AgNPs was negative, indicating the stability of the synthesized nanoparticles. TEM analysis highlighted the formation of spherical AgNPs. The biosynthesized AgNPs showed antibacterial and antifungal activities. Remarkably, AgNPs coated with propolis extract have improved antioxidant properties as compared with the original propolis extract, due to the preferential affinity of AgNPs for biomolecules with antioxidant properties. Finally, the AgNPs have efficiency to degrade malachite green, under solar irradiation, within 5 hours of exposure, therefore being a rapid, economic and ecological choice to remove organic dyes from ecosystem.

\section{Acknowledgement}

This publication is part of a project that has received funding from the European Union's Horizon 2020 research and innovation programme under grant agreement No 667387 WIDESPREAD 2-2014 SupraChem Lab and by a grant of the Romanian Ministry of Research and Innovation, CCCDI UEFISCDI, project number PN-III-P1-1.2-PCCDI2017-0697/13PCCDI/2018, within PNCDI III.

\section{References}

1. Ahmad N, Sharma S, Alam MK, Singh V, Shamsi S, Mehta B, Fatma A, Rapid synthesis of silver nanoparticles using dried medicinal plant of basil. Colloids Surf B., 2010; 81(1): 81-86.

2. Akter M, Sikder MT, Rahman MM, Ullah AKMA, Hossain KFB, Banik S, Hosokawa T, Saito T, A systematic review on silver nanoparticles-induced cytotoxicity: Physicochemical properties and perspectives. J Adv Res., 2018; 9: 1-16.

3. Bar H, Bhui DK, Sahoo GP, Sarkar P, Misra A, Green synthesis of silver nanoparticles using latex of Jatropha curcas. Colloids Surf A., 2009; 339(13): 134-139.

4. Cha CJ, Doerge DR, Cerniglia CE, Biotransformation of malachite green by the fungus Cunninghamella elegans. Appl Environ Microbiol., 2001; 67(9): 4358-4360.

5. Chen X, Zheng Z, Ke X, Jaatinen E, Xie T, Wang D, Guo C, Zhao J, Zhu H, Supported silver nanoparticles as photocatalysts under ultraviolet and visible light irradiation. Green Chem., 2010; 12: 414-419.

6. Daleprane JB, Abdalla DS, Emerging roles of propolis: antioxidant, cardioprotective, and antiangiogenic actions. Evid Based Complement Alternat Med., 2013; 2013(Art ID175135):1-8.

7. Drăgoi CM, Olaru OT, Dinu M, Popescu C, Arsene AL, Dune A, Nicolae AC, Ancuceanu RV, Zbârcea CE, Negreș S, Niţulescu GM, Şeremet OC. Characterisation, pharmacotoxicological and biochemical studies on Morus alba L. extract and its fractions. Farmacia. 2018; 66(1): 120-128.

8. Dwivedi AD, Gopal K, Biosynthesis of silver and gold nanoparticles using Chenopodium album leaf extract. Colloids Surf A., 2010; 369(1): 27-33.

9. Geethalakshmi R, Sarada DV, Gold and silver nanoparticles from Trianthema decandra: synthesis, characterization, and antimicrobial properties. Int J Nanomed.. 2012; 7: 5375-5384.

10. Gopinath V, MubarakAlib D, Priyadarshini S, Priyadharsshini NM, Thajuddin N, Velusamy P, Biosynthesis of silver nanoparticles from Tribulus terrestris and its antimicrobial activity: a novel biological approach. Colloids Surf B., 2012; 96: 69-74.

11. Haleemkhan AA, Naseem B, Vardhini V, Synthesis of nanoparticles from plant extracts. Int J Modern Chem Appl Sci., 2015; 2(3): 195-203.

12. Heydari R, Biological applications of biosynthesized silver nanoparticles through the utilization of plant extracts. Herb Med J., 2017; 2(2): 87-95.

13. Iancu $C$, Cioancă $O$, Hăncianu $M$, Mircea $C$, Phytochemical profile of two cultivated Pelargonium (Geraniaceae) species. Farmacia, 2016; 64(6): 840-843.

14. Ioannou E, Poiata A, Hancianu M, Tzakou O, Chemical composition and in vitro antimicrobial activity of the essential oils of flower heads and leaves of Santolina rosmarinifolia L. from Romania. Nat Prod Res., 2007; 21(1): 18-23.

15. Jain D, Daima HK, Kachhwaha S, Kothari SL, Synthesis of plant-mediated silver nanoparticles using papaya fruit extract and evaluation of their antimicrobial activities. Dig $J$ Nanomater Bios., 2009; 4(4): 723-727.

16. Kagithoju S, Godishala V, Nanna RS, Eco-friendly and green synthesis of silver nanoparticles using leaf extract of Strychnos potatorum Linn. F. and their bactericidal activities. 3Biotech, 2015; 5: 709-714.

17. Kahrilas GA, Wally LM, Fredrick SJ, Hiskey M, Prieto AL, Owens JE, Microwave-assisted green synthesis of silver nanoparticles using orange peel extract. ACS Sustainable Chem Eng., 2014; 2(3): 367-376.

18. Kaviya S, Santhanalakshmi J, Viswanathan B, Muthumary J, Srinivasan K, Biosynthesis of silver nanoparticles using Citrus sinensis peel extract and its antibacterial activity. Spectrochim Acta A Mol Biomol Spectrosc., 2011; 79(3): 594-598.

19. Khalil MMH, Ismail EH, El-Baghdady KZ, Mohamed $\mathrm{D}$, Green synthesis of silver nanoparticles sing olive leaf extract and its antibacterial activity. Arab J Chem., 2014; 7: 1131-1139.

20. Khatoon N, Mazumder JA, Sardar M, Biotechnological applications of green synthesized silver nanoparticles. J Nanosci Curr Res., 2017; 2(1): 1-8.

21. Krishnaraj C, Jagan E, Rajasekar S, Selvakumar P, Kalaichelvan P, Mohan N, Synthesis of silver nanoparticles using Acalypha indica leaf extracts and its antibacterial activity against water borne pathogens. Colloids Surf B., 2010; 76(1): 50-56.

22. Krishnaraj C, Ramachandran R, Mohan K, Kalaichelvan PT, Optimization for rapid synthesis of silver nanoparticles and its effect on phytopathogenic fungi. Spectrochim Acta A., 2012; 93: 95-99. 
23. Kumar DA, Palanichamy V, Roopan SM, Green synthesis of silver nanoparticles using Alternanthera dentata leaf extract at room temperature and their antimicrobial activity. Spectrochim Acta Part A: Mol Biomol Spectrosc., 2014; 127: 168-171.

24. Kumar R, Ghoshal G, Jain A, Goyal M, Rapid green synthesis of silver nanoparticles (AgNPs) using (Prunus persica) plants extract: Exploring its antimicrobial and catalytic activities. $J$ Nanomed Nanotechnol., 2017; 8(4): 1-8.

25. Kumar V, Kumar YS, Synthesis of stable, polyshaped silver and gold nanoparticles using leaf extract of Lonicera japonica L. Int J Green Nanotechnol., 2011; 3(4): 281-291.

26. Kumar TVR, Murthy JSR, Rao MN, Bhargava Y, Evaluation of silver nanoparticles synthetic potential of Couroupita guianensis Aubl., flower buds extract and their synergistic antibacterial activity. 3Biotech, 2016; 6(1): 92.

27. Latha D, Arulvasu C, Prabu P, Narayanan V, Photocatalytic activity of biosynthesized silver nanoparticle from leaf extract of Justicia adhatoda. Mech Mater Sci Eng., 2017; 9(1): 1-6.

28. Logeswari P, Silambarasan S, Abraham J, Synthesis of silver nanoparticles using plants extract and analysis of their antimicrobial property. J Saudi Chem Soc., 2015; 19(3): 311-317.

29. Malterud KE, Rydland KM, Inhibitors of 15lipoxygenase from orange peel. J Agric Food Chem., 2000; 48: 5576-5580.

30. Nayagam V, Gabriel M, Palanisamy K, Green synthesis of silver nanoparticles mediated by Coccinia grandis and Phyllanthus emblica: a comparative comprehension. App Nanosci., 2018; 8(3): 205-219.

31. Oliveira RN, Mancini MC, Oliveira FCSD, Passos TM, Quilty B, Thiré MDSM, McGuinness GB, FTIR analysis and quantification of phenols and flavonoids of five commercially available plants extracts used in wound healing. Matéria, 2016; 21(3): 767-779.

32. Padalia H, Moteriya P, Chanda S, Green synthesis of silver nanoparticles from marigold flower and its synergistic antimicrobial potential. Arab J Chem., 2015; 8: 732-741.

33. Patil S, Chaudhari G, Paradeshi J, Mahajan R, Chaudhari BL, Instant green synthesis of silverbased herbo-metallic colloidal nanosuspension in Terminalia bellirica fruit aqueous extract for catalytic and antibacterial applications. 3Biotech, 2017; 7(1): 36

34. Pop CE, Pârvu M, Arsene AL, Pârvu AE, Dan Cristian Vodnar, Monica Tarcea, Anca Maria Toiu, Laurian Vlase. Investigation of antioxidant and antimicrobial potential of some extracts from Hedera helix L. Farmacia. 2017; 65(4): 624-629.

35. Prakash P, Gnanaprakasam P, Emmanuel R, Arokiyaraj S, Saravanan M, Green synthesis of silver nanoparticles from leaf extract of Mimusops elengi, Linn. for enhanced antibacterial activity against multi drug resistant clinical isolates. Colloids Surf B., 2013; 108: 255-259.

36. Pugazhenthiran N, Anandan S, Kathiravan G, Udaya Prakash NK, Crawford S, Ashokkumar M, Microbial synthesis of silver nanoparticles by Bacillus sp. $J$ Nanoparticle, 2009; 11: 1811-1815.

37. Ramos AFN, Miranda JL, Propolis: a review of its anti-inflammatory and healing actions. $J$ Venom Anim Toxins Incl Trop Dis., 2007; 13(4): 697-710.

38. Rastogi L, Arunachalam J, Sunlight based irradiation strategy for rapid green synthesis of highly stable silver nanoparticles using aqueous garlic (Allium sativum) extract and their antibacterial potential. Mater Chem Phys., 2011; 129(1-2): 558-563.

39. Sathishkumar M, Sneha K, Won SW, Cho CW, Kim $\mathrm{S}$, Yun YS, Cinnamon zeylanicum bark extract and powder mediated green synthesis of nano-crystalline silver particles and its bactericidal activity. Colloids Surf B., 2009; 73(2): 332-338.

40. Shetty P, Supraja N, Garud M, Prasad TNVKV. Synthesis, characterization and antimicrobial activity of Alstonia scholaris bark-extract-mediated silver nanoparticles. J Nanostruct Chem., 2014; 4: 161-170.

41. Silva-Carvalho R, Baltazar F, Almeida-Aguiar C, Propolis: A complex natural product with a plethora of biological activities that can be explored for drug development. Evid Based Complement Alternat Med., 2015; 2015(Art ID206439): 1-29.

42. Singh RP, Magesh S, Rakkiyappan C, Ginger (Zingiber officinale) root extract: a source of silver nanoparticles and their application. Int J Bio-Eng Sci Technol., 2011; 2(3): 75-80.

43. Singleton VL, Orthofer R, Lamuela-Raventos RM, Analysis of total phenols and other oxidation substrates and antioxidants by means of FolinCiocalteu reagent. Methods Enzymol., 1999; 299: 152-178.

44. Sun Y, Zhang Y, Shi Y, Xiao X, Dai H, Hu J, Ni P, Li Z, Facile preparation of silver nanoparticle films as an efficient surface-enhanced Raman scattering substrate. Appl Surf Sci., 2013; 283: 52-57.

45. Tataringa G, Stan C, Mircea C, Jitareanu A, Zbancioc AM, Antioxidant evaluation of some coumarin derivatives. Farmacia, 2016; 64(4): 533-538.

46. Trifan A, Aprotosoaie AC, Brebu M, Cioanca O, Gille E, Hancianu M, Miron A, Chemical composition and antioxidant activity of essential oil from Romanian Satureja montana L. Farmacia, 2015; 63(3): 413-416.

47. Venkatesham M, Ayodhya D, Madhusudhan A, Veerabhadram G, Synthesis of stable silver nanoparticles using gum Acacia as reducing and stabilizing agent and study of its microbial properties: a novel green approach. Int J Green Nanotechnol., 2013; 4(3): 199-206.

48. Vijayakumar M, Priya K, Nancy FT, Noorlidah A, Ahmed ABA, Biosynthesis, characterization and anti-bacterial effect of plant mediated silver nanoparticles using Artemisia nilagirica. Ind Crops Prod., 2013; 41: 235-240. 